\title{
PEMERTAHANAN IDENTITAS KARAKTER BUDAYA MASYARAKAT SAMIN DI DESA MARGOMULYO BOJONEGORO
}

\author{
Nur Alfin Hidayati ${ }^{1}$, Siti Aniqoh Shofwani ${ }^{2}$ \\ 1'nikidanajwasalsabila@gmail.com, aniqoh2014@gmail.com² \\ ${ }^{1}$ Prodi Pendidikan Bahasa dan Sastra Indonesia, ${ }^{2}$ Prodi Ekonomi \\ ${ }^{1}$ IKIP PGRI Bojonegoro, ${ }^{2}$ STIE Ekonomi Semarang
}

\begin{abstract}
Abstrak
Artikel ini menganalisis perubahan sikap dan identitas budaya Masyarakat Samin di Desa Margomulyo. Fokus penelitian ini pada empat nilai karakter budaya: 1)Tidak mengambil milik orang lain (tidak mencuri); 2) Tidak berbicara kotor (sopan santun); 3) Pendirian kuat ; 4) Jujur. Hasil penelitian bahwa masyarakat Samin Desa Margomulyo yang masih tinggal di desa tersebut masih melestarikan budaya mereka sedangkan masyarakat Samin yang tinggal di luar Desa Margomulyo sebagian besar banyak nilai-nilai budaya mereka telah terdegradasi dari kehidupan. Degradasi tersebut berakibat adanya perubahan sikap masyarakat Samin yang tinggal di luar Desa Margomulyo. Walaupun secara umum ada sekelompok kecil orang yang masih memahami dan atau mempraktikkan tradisi, ada kecenderungan degradasi dalam nilai-nilai budaya. Ada beberapa faktor di balik kecenderungan ini, di antaranya adalah: pendidikan, hidup di kota, tempat kerja, budaya Jawa dan Islam, dan perkawinan campuran, sera pengetahuan dan sains. Menyadari potensi kepunahan dan pentingnya tradisi, beberapa upaya diambil oleh para pemimpin masyarakat samin yang bertujuan melestarikan budaya Samin. Bentuk pemertahanan melalui sosialisasi dalam bentuk ngangsu kaweruh Samin, festifal Kange Yune Samin yang dilakukan bulan sura setiap tahunnya dan tradisi upacara sura yang sesuai dengan perkembangan nilai islami.
\end{abstract}

Kata kunci: budaya, karakteristik, masyarakat samin, pemertahanan identitas.

\section{Abstract}

This article analyzes changes in attitude and cultural identity of the Samin Community in Margomulyo Village. The focus of this research is on four cultural character values: 1) Not taking the property of others (not stealing); 2) Not talking dirty (manners); 3) Strong establishment; 4) Honestly. The result of the research is that the Samin people of Margomulyo Village who still live in the village still preserve their culture while the Samin people who live outside Margomulyo Village are mostly many of their cultural values have been degraded from life. The degradation resulted in a change in the attitude of the Samin community who lived outside Margomulyo Village. Although in general there is a small group of people who still understand and / or practice tradition, there is a tendency for degradation in cultural values. There are several factors behind this trend, including: education, living in cities, workplaces, Javanese and Islamic culture, and mixed marriages, sera, knowledge and science. Recognizing the potential for extinction and the importance of tradition, several attempts were taken by the leaders of the Samin community aimed at preserving the Samin culture. The form of detention is through socialization in the form of ngangsu kaweruh Samin, Kange Yune Samin festivals which are held in the sura of each year and the tradition of sura ceremonies in accordance with the development of Islamic values.

Key words: characteristic, culture, retention of identity, samin community.

\section{PENDAHULUAN}

Indonesia merupakan negara yang mempunyai keanekaragaman sumber daya alam, suku dan ras dan beragam budaya kalau dilihat dari berbagai aspek kehidupan. Indonesia yang kaya akan budaya terdiri dari begitu banyak orang, budaya dan peradaban (Mulder, 2001: 47). Budaya sebagai salah satu sarana persatuan terkadang membuka peluang untuk terjadinya degradasi diberbagai lini kehidupan seperti moral, etika, dan sebagai sarana aturan, budaya menjadi sebuah kontrol perilaku sosial.

Keanekaragaman budaya di Indonesia yang terdiri dari berbagai etnis, suku, adat istiadat menjadi sebuah kekayaan budaya yang seharusnya dapat dikelola dengan baik. Budaya tersebut bukan hanya dikelola saja akan tetapi lebih

56 | Jurnal Kredo Vol. 3 No. 1 Oktober 2019 dari itu harus dilestarikan dan dikembangkan agar menjadi modal plus dalam pembangunan. Budaya di Indonesia tidak banyak yang masih dilestarikan dan dikembangkan karena sebagian sudah mulai terjadi degradasi dari identitas karakter budaya aslinya. Salah satunya adalah masyarakat masyarakat Samin di Desa Margomulyo Kecamatan Margomulyo Kabupaten Bojonegoro.

Di kota Bojonegoro ada beberapa kelompok etnis, salah satunya adalah etnis Samin. Ini adalah suku etnis yang tinggal di pinggiran Bojonegoro. Orang Samin memiliki nilai budaya mereka sendiri, hal itu bisa menjadi panduan terbaik mereka untuk hidup di masyarakat. Budayabudaya tersebut adalah: 1) Tidak mengambil milik orang lain (tidak mencuri); 2) Tidak berbicara kotor (sopan santun); 3) Pendirian kuat ; 4) Jujur. Hal 
tersebut menjadi memunculkan pertanyaan asal-usul budaya, apakah budaya itu ada sejak ada pengaruh Islam, atau awalnya berasal dari warisan budaya Jawa.

Budaya akan selalu berkembang dan selalu mengalami perubahan. Perubahan budaya merupakan sebuah proses dalam kehidupan manusia yang selalu terjadi sebuah bentuk perkembangan budaya termasuk budaya di Indonesia. Di sisi lain, ruang belajar menunjukkan perubahan nilai budaya terkini dari perilaku Indonesia sebagai perubahan yang baik. Dalam hal ini, penelitian dilakukan secara etnografis untuk mengidentifikasi nilai-nilai budaya masyarakat Samin di mana mereka identitas telah dibentuk oleh perubahan yang sedang berlangsung.

\section{KAJIAN TEORI}

Masyarakat dan budaya memiliki hubungan yang erat. Masyarakat tidak akan terlepas dengan budaya karena budaya merupakan bagian dari kehidupan masyarakat. Keanekaragaman masyarakat memengaruhi keanekaragaman budaya dalam masyarakat tersebut, begitu juga sebaliknya (Hidayati dkk., 2019). Kenyataan kini, banyak budaya tradisional masyarakat Jawa yang sarat akan makna, nilai, dan unsur indigenous luntur dan hilang bahkan punah karena tersisih kebudayaan asing. Mestinya budaya harus dilestarikan dan dikembangkan menjadi kekuatan daya tarik dan keunikan suatu masyarakatnya. Budaya merupakan aset yang tak ternilai dan kekayaan yang menjadikan masyarakatnya memiliki hasil budi dan karya sebagai keunikan masyarakat tersebut.

Kebudayaan adalah keseluruhan gagasan dan karya manusia yang harus dibiasakannya dengan belajar, beserta keseluruhan dari hasil budi dan karyanya itu (Koentjaraningrat, 2004: 9). Cakupan budaya adalah bahasa, tatanan sosial, pencarian nafkah, pengetahuan, kesenian, teknologi dan religi. Sistem budaya inilah yang menjadi pedoman, pendorong dan sekaligus sebagai pengawas atas segala sikap, tingkah laku, dan tindakan para warga masyarakat dalam mengatur berbagai pranata sosial (Nurudin, 2003: 75). Termasuk identitas dan sikap pada masyarakat Samin Dusun Jepang Desa Margomulyo Bojonegoro yang menjadi budaya khas masyarakatnya. Masyarakat Samin merupakan bagian dari masyarakat Jawa (Hidayati dkk., 2018).

Identitas budaya jawa merupakan butir-butir kecerdasan, kebijaksanaan asli yang dihasilkan oleh masyarakat budaya jawa (Mojo dkk., 2017: 2505). Nilai-nilai berkaitan dengan budaya karena budaya memiliki nilai-nilai yang diwariskan, ditafsirkan, dan dilaksanakan seiring dengan proses perubahan masyarakat (Yunus, 2014: 1). Kajian mengenai kebudayaan tradisional mengenai identitas dan sikap yang terkandung di dalamnya sudah selayaknya perlu dikembangkan. Hal ini sebagai manifestasi apresiasi masyarakat untuk mewujudkan pelestarian budaya leluhur. Diketahui bersama, warisan leluhur merupakan salah satu identitas penting yang menunjukkan keotentikan budaya dalam masyarakat tertentu (Hidayati dkk., 2019). Keautentikan budaya penting untuk menjadi jati diri masyarakat yang memilikinya.

\section{METODE PENELITIAN}

Studi tentang pemertahanan identitas karakter pada masyarakat Samin dilakukan di Dusun Jepang Desa Margomulyo Kecamatan Margomulyo Kabupaten Bojonegoro. Penelitian ini adalah penelitian kualitatif. Jenis penelitian ini adalah deskriptif kualitatif, yaitu dengan melakukan penelitian terhadap objek-objek yang menemukan dan menafsirkan hubungan berbagai elemen di dalamnya (Miles \& Huberman, 1992: 24). Teknik pengumpulan data dalam penelitian ini adalah observasi, wawancara, dan meninjau dokumen dan arsip (analisis isi). Data yang diambil dari observasi ini adalah aktivitas keseharian, baik aktivitas perilaku sosial, status sosial, tradisi dan 
kebudayaannya. Data yang diambil dari wawancara ini adalah wawancara antara informan dan pewawancara, dengan jumlah 7 orang yang diwawancarai mewakili masing-masing kelompok dan sumber utama. Data yang diambil dari dokumen dan arsip berupa buku-buku, karya ilmiah, atau penulisan yang berkaitan dengan teks-teks yang relevan dengan tema yang dikaji, dokumen visual yang berkaitan dengan foto-foto aktifitas kebudayaan masyarakat samin. Teknik analisis data dalam penelitian ini adalah analisis deskriptif kualitatif dan interaktif, analisis data berfokus pada makna, deskripsi, dan penempatan data pada masing-masing konteks (Moelong, 2013: 67).

\section{HASIL DAN PEMBAHASAN}

\section{Identitas Samin}

Masyarakat Samin adalah salah satu kelompok masyarakat yang masih memiliki dan mempertahankan landasan perilaku sosial mereka dengan mendasarkan pada nilai-nilai tradisional yang mereka yakini. Masyarakat Samin menggunakan ajaran Saminisme sebagai pedoman hidup dan perilaku keseharian. Dengan menggunakan metode oral (tradisi lisan), ajaran Saminisme mampu bertahan dari akhir abad 19 sampai sekarang (Mulder, 2001: 47).

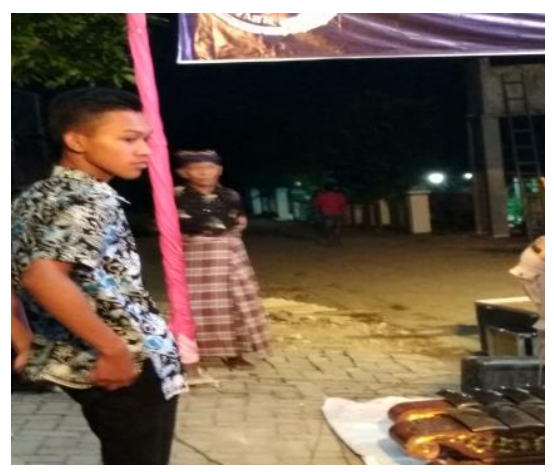

Gambar 1 interaksi masyarakat Samin dengan non Samin

Berdasarkan hasil observasi, sekarang ini masyarakat Samin mulai membuka diri dari kebudayaan luar, terbukti adanya interaksi antara masyarakat Samin dengan penduduk yang $\mathbf{5 8}$ | Jurnal Kredo Vol. 3 No. 1 Oktober 2019 notabene sudah modern. Seiring adanya interaksi yang dilakukan oleh masyarakat Samin maka tanpa disadari identitas Samin yang dahulu sangat khas dibandingkan dengan masyarakat lain baik secara berpakaian, bentuk rumah, bicara (bahasa), adat istiadat, nilai norma, bahkan tradisi kebudayaanya pada masyarakat Samin pun mengalami perubahan yang sekarang ini telah menjadi seperti masyarakat pada umumnya (masyarakat non Samin). Masyarakat berada dalam proses perubahan, bergerak secara dimanis mengikuti pola tertentu berdasarkan faktor-faktor yang melingkupinya,hal yang seperti itu telah terjadi pada masyarakat Samin (Ahmadi, 2002: 54).

\section{Perubahan Budaya dan Sikap Masyarakat Samin}

Memiliki budaya dan tradisi di antara masyarakat Samin memudar atau masih utuh? Pertanyaan ini adalah fokus dari penelitian ini. Data menunjukkan bahwa ada degradasi di antara orang-orang yang tinggal di kota itu mereka tidak lagi mempertahankan tradisi. Namun, kasusnya berbeda dengan orang-orang di sisi lain atau lebih lagi di Dusun Jepang Desa seperti Margomulyo. Ada beberapa faktor di balik ini, di antaranya adalah fakta bahwa populasi di pedesaan dan atau desa Margomulyo masih didominasi oleh masyarakat Samin. Faktor lainnya adalah kepemimpinan. Sangat umum untuk menemukan bahwa jika pemimpin berasal dari Masyarakat Samin, maka budaya dan tradisi Samin akan tetap ada dengan kuat. Desa lain seperti Samin Ngraho juga ditambahkan ke teori. Bahkan untuk membuatnya lebih jelas, desa Tapelan yang dipimpin oleh Samin ternyata kurang dalam menjaga budaya dan tradisi. Secara geografis, desa ini juga lebih dekat ke kota tapi di sana tidak ada tradisi yang menyertai setiap kesempatan.

Masyarakat Samin yang masih tinggal di Dusun Jepang Desa Margomulyo kalau dilihat dari identitas karakter budayanya masih mempertahankan sikap karakter/ajarannya 
seperti untuk tidak mengambil milik orang lain (tidak mencuri), tidak berbicara kotor (sopan santun), pendirian kuat, sikap jujur. Berbeda dengan orang Samin yang sudah tinggal di luar/menikah dengan masyarakat desa lain telah banyak meninggalkan ajaran tersebut (Mukodi \& Burhanuddin, 2016: 399) .

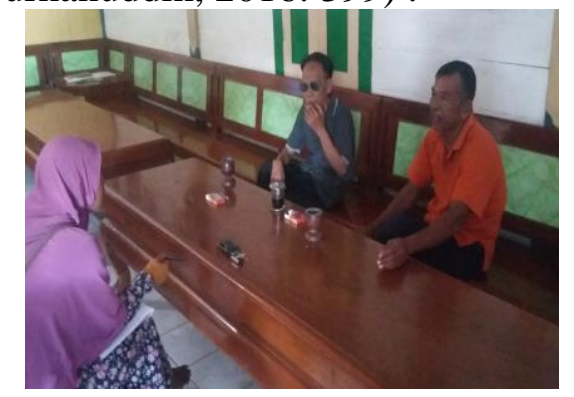

Gambar 2 Wawancara dengan pimpinan Samin dan Kasun Jepang Margomulyo

Hasil wawancara dengan pimpinan Samin menunjukkan bahwa perubahan masyarakat Samin yang tinggal di luar desa/kota lain sudah mulai terpengaruh dengan budaya luar dan ajaran Samin sedikit demi sedikit tergerus oleh perubahan hasil interaksi dengan budaya luar. Mbah Hardjo Kardi selaku pimpinan Samin juga mengatakan bahwa "Samin yang masih asli itu yang tinggal di Dusun Jepang Desa Margomulyo Bojonegoro, kalau yang sudah keluar dari desa (di kota) sudah mulai terpengaruh dengan budaya luar".

Perubahan budaya terjadi di setiap ujung dunia ini, menurut Moscovic (2013: 7), umat manusia dalam nilai budaya secara progresif cenderung menuju keseragaman. Dalam hal budaya, keseragaman tidak hanya berarti kerugian warisan budaya tetapi juga memiliki standar baru yang berbeda di dalam kehidupan. Itu ada hubungannya dengan nilai tradisi yang tidak sepenuhnya memahami dan diterapkan oleh masyarakat. Empat identitas masyarakat Samin di Dusun Jepang perubahannya dapat dilihat dari empat sikap: tidak mengambil milik orang lain (tidak mencuri), tidak berbicara kotor (sopan santun), pendirian kuat, sikap jujur.
Perubahan budaya dan sikap masyarakat Samin di luar desa tersebut hasil akulturasi dari budaya luar dan Samin itu sendiri melalui saluran lingkungan seperti tempat kerja, budaya Islam, budaya Jawa, pengaruh pendidikan, adanya perkawinan campuran, pengembangan pengetahuan dan sains yang semuanya saling mempengaruhi. Pendidikan akan ikut mempengaruhi pola pikir dan sikap mereka, melalui pendidikan pengetahuan dan kreativitas budaya dapat berkembang menyesuaikan zamannya meskipun terkadang mengarah pada hal positif ataua negatif. Pernikahan percampuran akan mempengaruhi budaya dan kolaborasi percampuran budaya keduanya. Tempat kerja ikut mempengaruhi budaya melalui interaksi antara satu orang dengan yang lainnya dan semuanya saling mempengaruhi. Budaya Jawa dan Islam juga akan ikut andil akan adanya perubahan sikap dan identitas Samin. Saluran-saluran tersebut akan ikut mengadopsi nilai-nilai budaya lainnya. Faktor pengembangan sains dan teknologi yang juga tidak bisa diabaikan sebagai penyebab perubahan dalam sikap dalam masyarakat Samin.

\section{Melestarikan Identitas Budaya dan Sikap Masyarakat Samin}

Unsur nilai budaya seperti tidak mengambil milik orang lain (tidak mencuri), tidak berbicara kotor (sopan santun), pendirian kuat, sikap jujur, dan lain-lain di masyarakat Samin dapat diartikan sebagai kekuatan yang dimiliki oleh setiap individu untuk mendukung mereka tumbuh dan berkembang dengan cara yang positif. Di sini, setiap elemen budaya dapat menjadi potensi mereka di dalamnya menyajikan kehidupan ke masa depan. Sebaliknya, jika elemen-elemen itu ditafsirkan dan digunakan secara negatif maka itu memang akan berdampak negatif terhadap kehidupan orang orang. Sebagai contoh, tidak mengambil milik orang lain (tidak mencuri) dalam ajaran Samin, barang apapun yang bukan miliknya tidak akan diambil mesikipun di jalan tanpa 
pemilik. Mengambil milik orang lain berarti melakukan hal-hal yang bertentangan dengan hukum adat atau nilai-nilai moral. Nilai-nilai budaya seperti tidak mengambil milik orang lain (tidak mencuri), tidak berbicara kotor (sopan santun), pendirian kuat, sikap jujur ini perlu dipupuk dan terus dijaga sebagai identitas Samin. Mbah Hardjo Kardi selaku pemimpin selalu berusaha memberikan tauladan dan tetap memegang ajaran Samin sebagai bentuk nilai unik yang dimiliki Samin. Mbah Hardjo Kardi mengatakan bahwa "Wong Samin ya kudu ngerti Samine, mesti jujur, ora srei, ora geleman, lan njaga latine ben ora nglarani uwong liya". Nilai unik tersebut dapat dijadikan sebuah identitas yang sering disebut dengan karakter (Lickona, 1991: 20).

Menyadari potensi kepunahan dan pentingnya tradisi, beberapa upaya diambil oleh para pemimpin masyarakat Samin yang bertujuan melestarikan budaya Samin. Bentuk pemertahanan melalui sosialisasi dalam bentuk ngangsu kaweruh Samin, festifal Kange Yune Samin yang dilakukan bulan sura setiap tahunnya dan tradisi upacara sura yang sesuai dengan perkembangan nilai Islami.

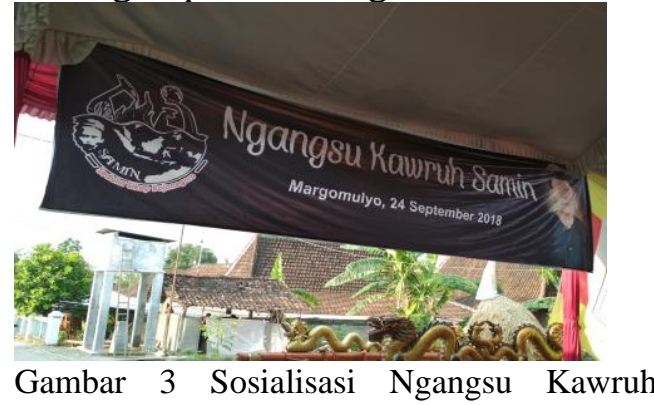
Samin

Masyarakat Samin merupakan bagian dari budaya Jawa yang masyarakatnya menganut beragama Islam sehingga pimpinan Samin menyadari hal tersebut, cara yang diambil untuk mempertahankan identitas dan sikap Samin dengan melakukan pendekatan dengan budaya Jawa dan Islam.

\section{SIMPULAN}

Identitas masyarakat Samin di Dusun Jepang Desa Margomulyo Kecamatan Margomulyo Kabupaten Bojonegoro terdiri dari dua bagian: terutama di daerah pedesaan di mana religiusitas serta pendidikan cenderung rendah. Namun, dalam hal nilai-nilai budaya pada aspek lain seperti tidak mengambil milik orang lain (tidak mencuri), tidak berbicara kotor (sopan santun), pendirian kuat, sikap jujur, itu dapat dikatakan mereka mengakar kuat di dalam komunitas. Hal ini berbanding terbalik dengan Samin yang ada di kota atau di luar Dusun Jepang Desa Margomulyo memperlihatkan kecenderungan yang berbeda. Di antara mereka, budaya nilai mulai punah termasuk nilai-nilai seperti tidak mengambil milik orang lain (tidak mencuri), tidak berbicara kotor (sopan santun), pendirian kuat, sikap jujur. Semua perubahan ini menghasilkan nilai perubahan sikap dan tindakan. Perubahan budaya dan sikap tersebut hasil akulturasi dari budaya luar dan dan Samin itu sendiri melalui saluran lingkungan seperti tempat kerja, budaya Islam, budaya Jawa pengaruh pendidikan, adanya perkawinan campuran, pengembangan pengetahuan dan sains yang semuanya saling mempengaruhi. 


\section{DAFTAR PUSTAKA}

Ahmadi, Abu. 2002. Psikologi Sosial. Jakarta: PT Rineka Cipta.

Hidayati, NA., Herman J.W., Retno W., Suyitno. 2017. Ritual Animism and Religious on Sura Thanksgiving Ceremony of Samin Jepang Margomulyo Tribe Community. ICIGR. Advances in Social Science, Education and Humanities Research (ASSEHR), vol. 125 , Pp. 348-353.

Hidayati, NA., Herman J.W., Retno W., Suyitno. 2018. Integrating Javanese Samin Culture and Islam Precepts In Sura. Proceedings of the 1st International Conference on Science and Technology for an Internet of Things, Eudl Proceding, https://eudl.eu/pdf/10.4108/eai.19-10-2018.2282549.

Hidayati, NA., Herman J.W., Retno W., Suyitno. 2019. Islamic Values of Sura Ceremony Done by Samin People in Jepang, Margomulyo, Bojonegoro as Character Education for Undergraduates. Proceedings of the 1st Seminar and Workshop on Research Design, for Education, Social Science, Arts, and Humanities, eudl. https://eudl.eu/pdf/10.4108/eai.27-4-2019.2286892

Koentjaraningrat. 2000. Pengantar Ilmu Antropologi. Jakarta: Rineka Cipta.

Lickona, Thomas. 1991. Educating for character. New York: Bantam Books.

Miles, M.B. and A. M. Huberman. 1992. Qualitative Data Analysis A Sourcebook of New Methods, Sage, Beverly Hill.

Mojo, Endrat; Hadi, Sudharto; Purnaweni, Hartuti. 2017. Sedulur Sikep's Environmental Wisdom in Conservation of North Kendeng Mountains Sukolilo. Advanced Science Letters, Volume 23(3), pp. 2504-2506.

Moleong, Lexy J. 2013. Metode Penelitian Kualitatif Edisi Revisi, Bandung: Remaja Rosdakarya.

Moscovici, Serge, 2000, Social Representations: Explorations in Social Psychology, Polity Press.

Mukodi \& Burhanuddin, Afid . 2016. Islam Abangan dan Nasionalisme Masyarakat Samin di Blora. Jurnal Penelitian Sosial Keagamaan. 24 (2), 379-400.

Mulder, Niels. 2001. Mistisisme Jawa: Ideologi Di Indonesia, Cetakan pertama, LKiS, Yogyakarta.

Nurudin (Editor), 2002, Agama Tradisional, UMM Press, Malang.

Sripun, Mattara, Sekson Yongvanit and Richard Pratt. 2017. Power Ligitimacy an Urgency of Community-Based Tourism Stakeholders in Northeastern Thailand. Asian Social Science, 13 (4), 104-116.

Yunus, Rasid. 2014. Nilai-Nilai Kearifan Lokal (Local Genius) Sebagai Penguat Karakter Bangsa: Studi Empiris Tentaang Huyula. Yogyakarta: Deepublish. 